\title{
What happened to cauda equina fibers? Adhesive arachnoiditis
}

\author{
Turgay Kara, Ömer Davulcu $\bowtie$, Fatih Ateş $\bowtie$, Fatma Zeynep Arslan $\bowtie$, \\ Halil Ibrahim Sara $\bowtie$, Aslan Akin $\otimes$ \\ Affiliation: Department of Radiology, University of Health Science, Konya Training and Research Hospital, Konya, Turkey.
}

Correspondence: Turgay Kara, Mobile: 90 5055197559; E-mail: trgykr@gmail.com

\section{Abstract}

Spinal arachnoiditis may present with low back pain, foot pain, loss of sensation and motor weakness. In addition, some people may have syringomyelia due to impaired flow of cerebrospinal fluid. In the etiology, there are infections, intrathecal steroid or anesthetic injection, trauma, subarachnoid hemorrhage, myelographic contrast media, multiple spinal surgery and lumbar puncture history. The patient's past treatment history, clinical and MRI examination are important in diagnosis. In this case, we aimed to discuss postoperative adhesive arachnoiditis which caused low back pain, and imaging findings in the light of literature.

Key words: Adhesive arachnoiditis; Cauda equina; Pain; Anesthesia; Surgery; Imaging; MRI

Citation: Kara T, Davulcu O, Ates F, Arslan FZ, Sara HI, Akin A. What happened to cauda equina fibers? Adhesive arachnoiditis. Anaesth. pain intensive care 2020;24(5):555-557

Received: 29 April 2020, Reviewed: 17 June 2020, Accepted: 18 June 2020

\section{Introduction}

Spinal arachnoiditis was first described in $1909 .{ }^{1}$ It may be asymptomatic and may present with back and leg pain and loss of power. In addition, some people may have syringomyelia due to impaired flow of cerebrospinal fluid. ${ }^{2}$ In the etiology there are infections, intrathecal steroids or anesthetic injections, trauma, subarachnoid hemorrhage, myelographic contrast agent, multiple spinal surgery. ${ }^{3,4}$ When the patient was admitted with low back pain or taken lumbar Magnetic Resonance Imaging (MRI) for another reason, if the detailed anamnesis was not written and / or cannot be compared with the old images, it leads to confusion in diagnosis. Anamnesis, clinical findings and MRI examination of the patient have critical importance in diagnosis. ${ }^{5,6}$

\section{Case report}

A 40-year-old woman was referred to the radiology department for a lumbar MRI examination. The patient had no detailed anamnesis because of being a very busy state hospital, it was observed that cauda equina
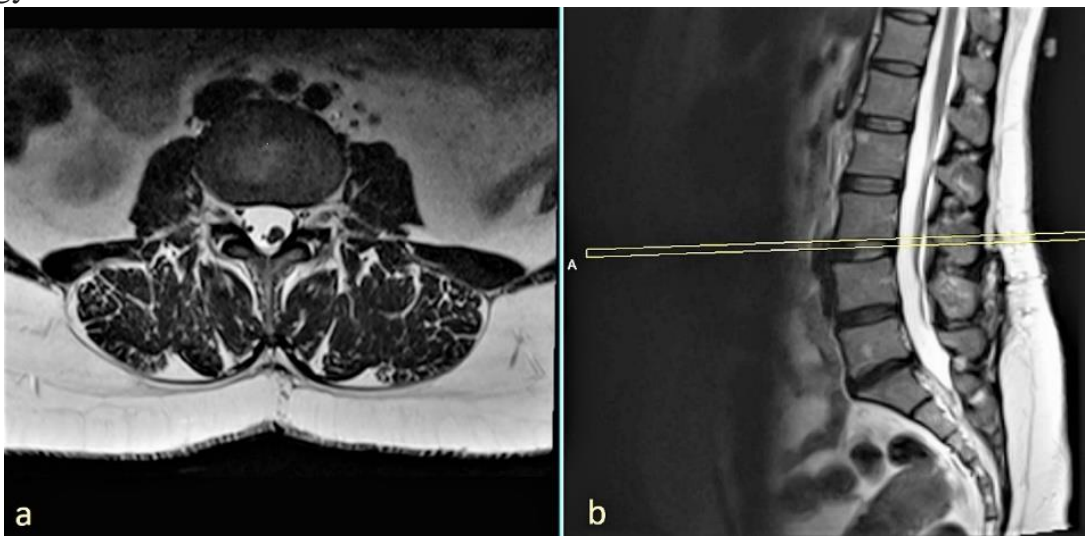

Figure1: Axial (a) and sagittal (b) MRI images. Axial image shows adherent cauda equina fibers in cross section passing L3-L4 level 
fibers were atypically nodular and thickened at the first look on MRI (Figure 1).

A structural or congenital anomaly was suspected in the first stage. However, when the hospital PACS system was examined retrospectively, it was seen that cauda equina fibers were discrete and normal in lumbar MRI of the patient taken 1 year ago. In addition to that, a disc protruding to the spinal canal at the level of L4L5 was detected (Figure 2). When the patient's history was questioned in depth, it was learned that he had complaint low back pain for two years She was treated intermittently at different pain clinics by multiple medical, physical, and complementary therapies with no obvious relief and underwent surgery for L4-L5 current MRI was re-evaluated in the light of this information, L5 level left laminectomy defect was observed (Figure 3). Finally the patient was diagnosed with postoperative adhesive arachnoiditis. The patient was referred to algology department.

\section{Discussion}

The common symptoms of arachnoiditis are nonspecific and difficult to differentiate from other neural compressive disorders. Symptomatic spinal arachnoiditis is an inflammatory process. The scar formation occurring in this process affects the arachnoid membrane and leptomeninges. ${ }^{4}$ This inflammatory process extends up to 3 meningeal layers

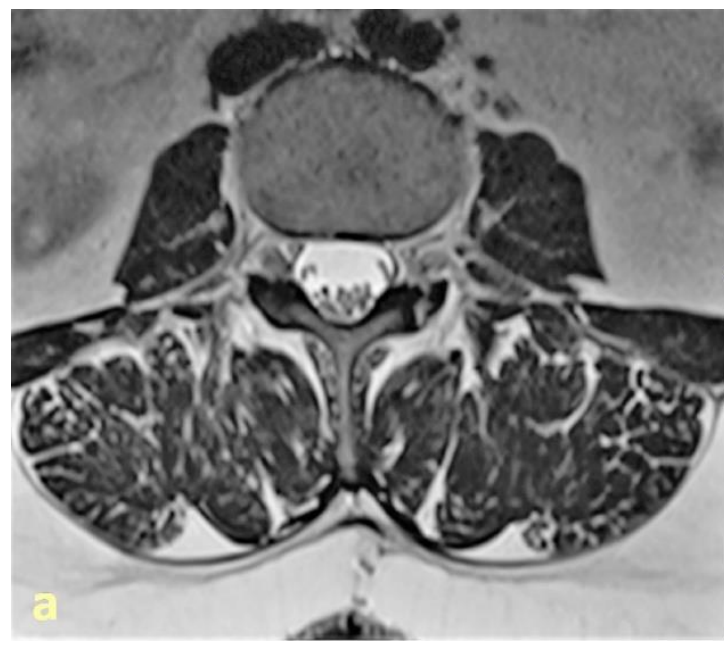

Figure 2: Axial (a) and sagittal (b) MRI images. Axial image shows normal separate cauda equina fibers in cross section passing L3-L4 level

disc herniation 6 months ago. After the surgery, she had no pain for a few weeks, but then her pain began again because of that she had an epidural corticosteroid injection but her pain worsened. She was administrated opioids. She had no myelogram and no chronic disease story such as connective tissue. $\mathrm{X}$ rays were not indicative. Lab tests were normal. Prolonged standing, driving, and walking was provoking pain and radiation into her legs. On physical examination, there was tenderness over lumbar spine with lower limbs upper motor neuron weakness. When the

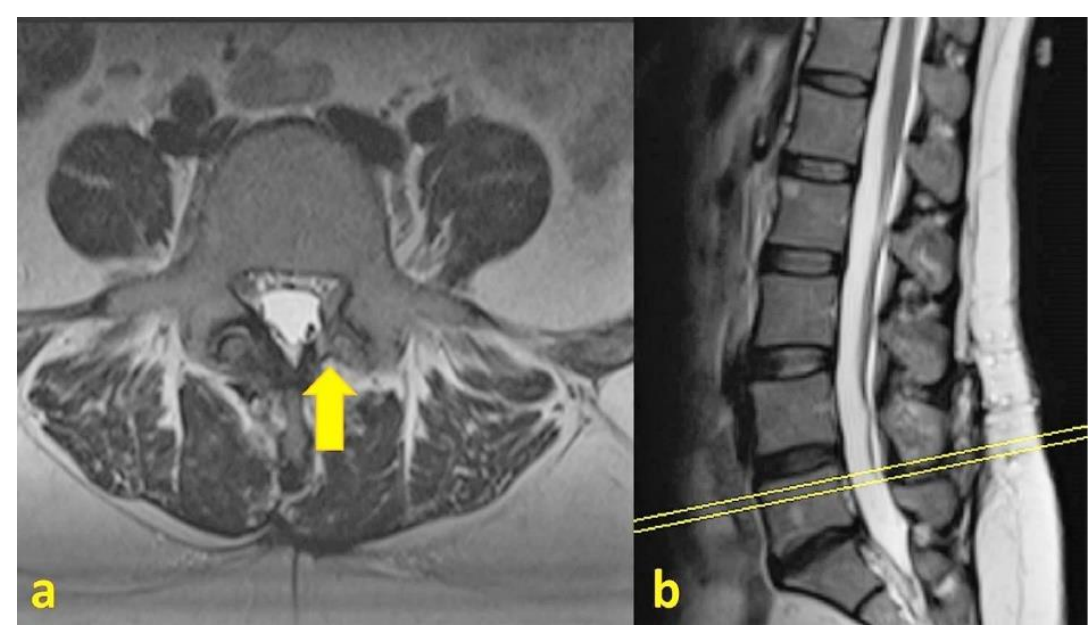

Figure 3: Axial (a) and sagittal (b) MRI images. There is a laminectomy defect on left L5 vertebra 
In MRI, subarachnoid cysts, irregularities on the surface of the spinal cord, complex fistulas in the spinal cord, compression of the cord by arachnoid loculations, cord withdrawal by adhesions, formation of septa in the cord can be detected. ${ }^{7,8,9}$

Arachnoiditis is divided into 3 groups in MR imaging. ${ }^{8}$

Type I: nerve roots are clumped together and distorted

Type II: nerve roots are adherent to the theca resulting in an empty thecal sac sign

Type III: nerve roots and theca are clumped together into a single soft tissue mass centrally within the spinal canal

Our case entered into group 1 because the arachnoid fibers were clustered in the middle of thecal sac.

In the differential diagnosis, the leptomeningeal carcinoma originating from the nerve roots must be separated from the systemic tumors that spread through the blood and hold the spinal cord. In addition, it is necessary to separate from the tumors such as glioblastoma, medulloblastoma and ependymoma, which can spread the cauda equina fibers through the cerebrospinal fluid. ${ }^{9,10}$ It should also be distinguished from diseases that hold arachnoid fibers like cauda equina syndrome.

Most patients with spinal arachnoiditis are treated with epidural or steroid injections. Surgical options are limited for these patients because surgery may increase the amount of scar tissue and inflammation within the thecal sac leading the risk of neurologic deficits. Surgical options include thecal endoscopy, neural stimulation, arachnoidolysis, flexible endoscopy, and subarachnoid-subarachnoid shunting. These surgical techniques have shown short-term improvements in pain, however most patients returned to back or worsened in the long term. ${ }^{11}$ There are a few researches that claim early systemic steroid administration may prevent inflammation and scar tissue.

Anamnesis and experienced radiologist and suspicion are important in their differential diagnosis such as our case.

\section{Conclusion}

Adhesive arachnoiditis may develop after spinal surgery. In patients with low back pain and those with atypical appearance of cauda equina fibers on MRI, adhesive arachnoiditis should be considered in the differential diagnosis. MRI can be used in the diagnosis of adhesive arachnoiditis and monitoring progression.

\section{Authors' contribution}

TK: Concept, conduction of the study work and manuscript editing

ÖD, HIŞ: manuscript editing
FA, FZA: Critical review

AA: In-charge of the case, reporting images

\section{References}

1. Rice I, Wee MYK, Thomson K. Obstetric epidurals and chronic adhesive arachnoiditis. $\mathrm{Br} J$ Anaesth. 2004;92:109-120. [PubMed] DOI: 10.1093/bja/aeh009

2. Pasoglou V, Janin $N$, Tebache $M$, Tegos TJ, Born JD, Collignon L. Familial Adhesive Arachnoiditis Associated with Syringomyelia. AJNR Am J Neuroradiol. 2014 Jun;35(6):1232-1236. [PubMed] DOI: 10.3174/ajnr.A3858

3. Ribeiro $C$, Reis FC. Adhesive lumbar arachnoiditis. Acta Med Port. 1998;11:59-65. [PubMed]

4. Etchepare F, Roche B, Rozenberg S, et al. Post-lumbar puncture arachnoiditis. The need for directed questioning. Joint Bone Spine. 2005;72:180-182. [PubMed] DOI: 10.1016/i.jbspin.2004.03.013

5. Delamarter RB, Ross JS, Masaryk TJ, Modic MT, Bohlman $\mathrm{HH}$. Diagnosis of lumbar arachnoiditis by magnetic resonance imaging. Spine (Phila $\mathrm{Pa}$ 1976). 1990;15:304-310. [PubMed] DOI: 10.1097/00007632199004000-00011

6. Ross JS, Masaryk TJ, Modic MT, Delamater R, Bohlman $\mathrm{H}$, Wilbur $\mathrm{G}$, et al. MR imaging of lumbar arachnoiditis. AJR Am J Roentgenol. 1987;149:10251032. [PubMed] DOI: $10.2214 /$ ajr.149.5.1025

7. Chiapparini L, Sghirlanzoni A, Pareyson D, Savoiardo M. Imaging and outcome in severe complications of lumbar epidural anaesthesia: report of 16 cases. Neuroradiology. 2000;42:564-571. [PubMed] DOI: 10.1007/s002340000359

8. Kunam VK, Velayudhan V, Chaudhry ZA, Bobinski M, Smoker WRK, Reede DL. Incomplete Cord Syndromes: Clinical and Imaging Review. Radiographics. $2018 \mathrm{Jul}-$ Aug;38(4):1201-1222. [PubMed] DOI: 10.1148/rg.2018170178

9. Shaw MD, Russell JA, Grossart KW. The changing pattern of spinal arachnoiditis. J Neurol Neurosurg Psychiatry. 1978;41:97-107. [PubMed] DOI: 10.1136/jnnp.41.2.97

10. Vloeberghs M, Herregodts $P$, Stadnik T, Goossens A, D'Haens J. Spinal arachnoiditis mimicking a spinal cord tumor: a case report and review of the literature. Surg Neurol. 1992;37:211-215. [PubMed] DOI: 10.1016/0090-3019(92)90233-d

11. Cornelson SM, Johnnie ED, Kettner NW. Neural Mobilization in a 54-Year-Old Woman With Postoperative Spinal Adhesive Arachnoiditis. J Chiropr Med. 2018 Dec; 17(4): 283-288. [PubMed] DOI: 10.1016/j.jcm.2018.07.004

12. Aldrete JA. Suspecting and diagnosing arachnoiditis. Pract Pain Manage. 2006;5(1):72-82. [Free Full Text] 